\title{
Global Risks and the Resilience of Future Health Care Systems
}

\section{Sarah Harper ${ }^{1}$}

Published online: 31 January 2020

(C) Springer Nature B.V. 2020

An electoral pattern is emerging across the globe. Boris Johnson in the UK, Donald Trump in the USA, Narendra Modi in India, Jair Bolsonaro in Brazil and right wing parties in in Australia, the Philippines, Hungary, Poland and Turkey. As a respected UK newspaper described the events:

"A new politics, funded by oligarchs, built on sophisticated cheating and provocative lies, using dark ads and conspiracy theories on social media, has perfected the art of persuading the poor to vote for the interests of the very rich" (Monboit, 2019).

A global transformation started in the early 1990s. What once seemed a linear progression towards greater democracy, more open markets and peaceful international cooperation appears to be weakening. Increasingly, globalisation will be driven by a new set of powers, within a new framework of understandings and values. Over the past decade, rising authoritarian regimes have begun to challenge the liberal international order. In particular increasing populism supported and facilitated by new technologies will place increasing pressure on a twentieth century multilateral framework developed under very different conditions. The world order looks to becomes more fragile and unpredictable.

It is against this background that the WEF 2020 Global Risks Report is published. While highlighting climate change as key in terms of both likelihood and impact, it also cautions on the current health care systems as being sufficiently resilient to address future health care risks and needs.

The institutions and approaches that have until now enabled health progress across the world are straining under gathering pressures and seem outmatched against new risks. Health systems around the world are at risk of becoming unfit for purpose. Changing societal, environmental, demographic and technological patterns are straining their capacity. (WEF 2020 Global Risk Report:75).

Highlighting falling life expectancies in many countries, slowing gains in health life span in high income and low and middle income countries, and increasing inequality in

Sarah Harper

sarah.harper@ageing.ox.ac.uk

1 Oxford Institute of Population Ageing, University of Oxford, Oxford, UK 
both life expectancy and healthy life expectancy within countries, it argues that health systems need new infrastructure, resources and skills, but in many parts of the world they are failing to adapt.

Like climate change, health risks pose an expensive and expanding transnational challenge. Around the world, health systems need to take a critical look at the fitness of their current approaches and institutions if we are to maintain the progress of the last century and tackle emerging threats. When health systems fail to mitigate vulnerabilities and adapt to changing contexts, they increase the likelihood of economic crises, political instability, social ruptures and state-on-state conflict (WEF 2020 Global Risk Report:79).

Non-communicable diseases and mental disorders have replaced infectious diseases as the leading threats to health and health systems worldwide. Once considered diseases of high income countries chronic and degenerative conditions are now a global epidemic accounting annually for 41 million deaths $85 \%$ of which are now are in low- and middle-income countries. 700 million people worldwide are estimated to have a mental disorder (Mnookin, S. 2016). As the WEF report, the four leading NCDsheart disease, cancer, diabetes and respiratory diseases, along with mental illness - may cost the global economy an estimated US\$47 trillion (in treatment and lost productivity) over the first 3 decades of the twenty-first Century, and dementia alone is expected to cost a further US\$2 trillion by 2030 .

All this is compounded by workforce limitations as most health systems are training and retaining too few doctors, nurses and other health workers; new technologies with associated risks of misuse, compromised patient safety and privacy, cyberattacks, increased costs and insignificant inequalities in access; and increased reliance on pharma with its exorbitant costs and inequality in coverage.

As the report concludes, good health is the foundation for societal well-being and a dynamic and prosperous economy. Health systems form part of countries' critical infrastructure, vital to security, resilience and growth. Well-functioning health systems enable countries to respond to, and recover from, natural and human-made disruptions. But a key threat to successful health care systems is fake news, and its ability to disrupt information about healthcare and preventive care, engendering fear and anxiety and leading to lack of compliance with health professionals' requests.

The modern world is complex, problems and solutions are complicated and rarely black and white. Yet increasingly people are being offered easy, populist answers by the new troupe of politicians. The future threatens a considerable increase in public expectations, combined with fake information on disease and health, growing unequal access therapies and deepening health inequalities within and across countries. This in itself will erode trust in health systems, leading to a decline in societal cohesion.

In his recent essay, Kahler (2018) proposes three future scenarios in terms of global governance: regional fragmentation as the global coalition falls apart under the rise of nationalism; stagnation as the new emerging powers - China, India and Brazil - rising to fill the vacuum left by the US face daunting obstacles to global leadership roles as their ability to devote resources to global initiatives is limited by domestic demands; and transformation of global governance involving increased co-operation with NGOs and Multi-national corporations. Currently, much world attention is focused on how these new institutional structures will tackle the global threat of climate change. But climate change will have outcomes, and a clear outcome is to significantly reduce global health, and compound the already severe challenges to the world's health care 
systems. The health of current and future generations are threatened by these linked challenges: the collapse of global institutions compounded by the rise of populist and nationalistic movements, facilitated and encouraged by the spread of fake information heralding easy solutions to complex problems.

Monboit, G The Guardian December 18th $2019+$.

WHO (World Health Organization). 2018. Noncommunicable Diseases. June 2018. https://www.who.int/news-room/fact-sheets/detail/noncommunicable-diseases;

Mnookin, S. 2016. "Out of the Shadows: Making Mental Health a Global Development Priority". World Bank and World Health Organization background paper.

Kahler, M. 2018. Global Governance: Three Futures. International Studies Review (2018) 20, 239-246.

Publisher's Note Springer Nature remains neutral with regard to jurisdictional claims in published maps and institutional affiliations. 